\title{
Basic structure of square and circle for defected waveguide structure
}

\author{
Shu Jia Chin ${ }^{1}$ and Mohamad Zoinol Abidin Abd. Aziz ${ }^{1, *}$ \\ ${ }^{1}$ Centre for Telecommunication Research and Innovation (CeTRI), Faculty of Electronic and Computer Engineering, \\ Universiti Teknikal Malaysia Melaka (UTeM), 76100 Durian Tunggal, Melaka, Malaysia
}

\begin{abstract}
Many existing waveguide designs focus on the application such as antenna and filter. Besides that, metamaterial used to design with waveguide is usually conducted by loading method. The configuration such as the walls or planes of waveguide is rarely proposed and designed. The motivation of this paper is to introduce the Defected Waveguide Structure (DWS) in waveguide to operate in Ultrawideband (UWB) frequency range. DWS is designed by using basic structure of square and circle. The square and circle are designed at all the walls of waveguide in patch. Hybrid design by mixing the square and circle is also proposed. The performance of DWS towards waveguide is analysed by using the transmission coefficient (S21) and reflection coefficient (S11). The filter circuit is constructed for modelling purpose to determine the value of inductance and capacitance. Copper waveguide acts as high pass filter at the frequency larger than cut off frequency $2.76 \mathrm{GHz}$. The square DWS design works as band pass filter with narrowest bandwidth of $5.19 \mathrm{GHz}$. The circle DWS design achieves the widest bandwidth of $6.55 \mathrm{GHz}$ for the pass band performance. Hybrid design improves the bandwidth slightly compare to square DWS design by $0.54 \mathrm{GHz}$.
\end{abstract}

\section{Introduction}

Waveguide plays important role in signal transmission. It has low loss and high-power handling which is widely applied in communication system. Yet, it costs expensive and bulky in size. Substrate Integrated Waveguide (SIW) technology is then proposed to solve the problem of larger size of waveguide [1]. The waveguide concept is applied with the planar microstrip feed line to be implemented in miniaturized device.

Waveguide design with metamaterial also become popular topic for the researchers by using the loaded method [2-5]. For instance, metamaterial plates loaded with periodic arrays of complementary-split-ringresonators is put inside waveguide for high power microwave generation [5]. However, it is found that the metamaterial design which contributes to the configuration of waveguide itself is seldom done. In [6], metamaterial is designed as anisotropic walls of waveguide where the configuration of waveguide itself is changed. Theoretical analytical approach is used to calculate the field distribution in waveguide [6].

Metamaterial receives great attention as it has been proposed to be useful in enhancing the performance of antenna [7-9]. Among all the types of metamaterial, defected structure is well known to design at ground plane and microstrip line [8-10]. It can be designed in slot or patch. The defected ground structure (DGS) at ground plane can improve return loss and achieve wider bandwidth when designs with microstrip antenna [8].
The defected microstrip structure (DMS) at microstrip line can perform as band stop filter [10]. However, a defected structure at the waveguide which can be called as defected waveguide structure (DWS) is not proposed yet which is the motivation of this paper. There is a room of opportunity and possible to introduce defect structure at waveguide instead of ground plane and microstrip feed line only.

As there is lack of information about shapes of DWS, this paper will propose the DWS design by using the basic structures which are square and circle. The square and circle are easy and simple to design. They are designed in patch form. The transmission coefficient (S21) and reflection coefficient (S11) are used to identify the performance of DWS of different structures towards waveguide. The operate frequency of waveguide is for Ultrawideband (UWB) applications.

\section{Defected waveguide structure design}

The rectangular waveguide is designed for the ease of fabrication. CST Microwave software is used to design and simulate waveguide. The waveguide dimension which is the width $(a)$ and height $(b)$ can be calculated from Equation (1) [4]. Cut off frequency $\left(f_{c}\right)$ is used to identify the waveguide dimension. As the rectangular waveguide for this paper operates in UWB frequency range from $3.1 \mathrm{GHz}-10.6 \mathrm{GHz}$, the lowest frequency is used to determine the waveguide dimension.

\footnotetext{
* Corresponding author: mohamadzoinol@utem.edu.my
} 


$$
f_{c}=\frac{1}{2 \pi \sqrt{\mu \varepsilon}} \sqrt{\left(\frac{m \pi}{a}\right)^{2}+\left(\frac{n \pi}{b}\right)^{2}}
$$

The rectangular waveguide is constructed to have copper layer at the inner wall of waveguide. The substrate used is FR4 with the specification listed in Table 1 below. The waveguide is designed with the width, $a=49 \mathrm{~mm}$ and height, $b=52 \mathrm{~mm}$ as shown in Figure 1. Two waveguide ports are located at both openended surface of waveguide.

Table 1. Specification of material used.

\begin{tabular}{|c|c|}
\hline Specification of material & Value \\
\hline Dielectric constant of substrate & 4.4 \\
\hline Tangent loss of substrate & 0.019 \\
\hline Thickness of substrate & $1.6 \mathrm{~mm}$ \\
\hline Thickness of copper & $0.035 \mathrm{~mm}$ \\
\hline
\end{tabular}

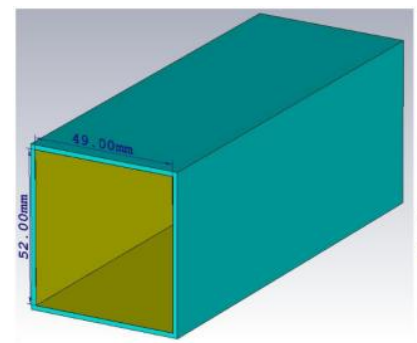

(a)

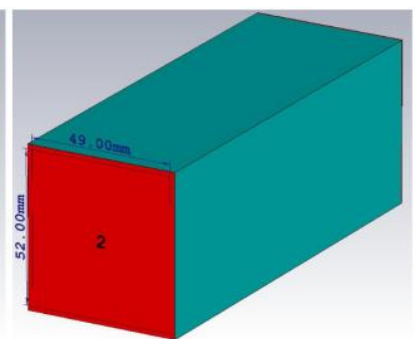

(b)
Fig. 1. The view of (a) copper waveguide and (b) waveguide ports at both open-ended of waveguide.

The basic structure of square with dimension of $6 \mathrm{~mm}$ $\mathrm{x} 6 \mathrm{~mm}$ is then located at the inner wall of waveguide. Example of square DWS design in waveguide is showed in Figure 2. There are 150 of squares with three rows at both side walls and two rows at top and bottom walls in waveguide. Each row consists of 15 of squares. The gap separation between the structure is set to $3 \mathrm{~mm}$. The total length of waveguide is $142 \mathrm{~mm}$ which is determined by the number of squares and gap separation used.

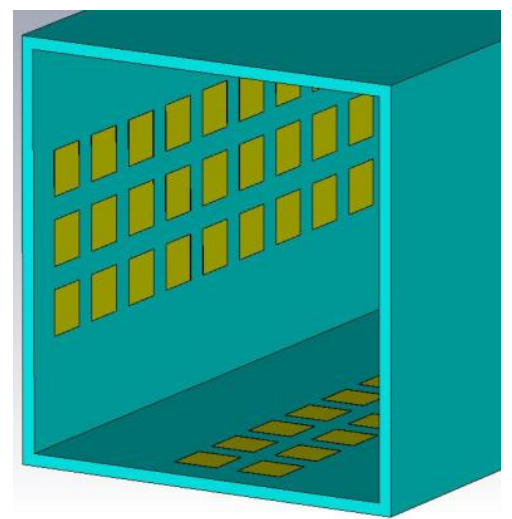

Fig. 2. The perspective view of square DWS design (Design B).
The squares can be then replaced by another shape which is circle structure. The circle has $3 \mathrm{~mm}$ of radius. Other parameters such as gap separation for square DWS design are kept constant to observe the effects between these two different basic structures. Meanwhile, a hybrid design which combines the structures of square and circle together is also designed to investigate the performances for both structures can be worked after combining. They are mixed in horizontally and vertically. Figure 3 shows the configuration of square DWS design (Design B), circle DWS design (Design C) and mixed square and circle DWS design (Design D) in waveguide.

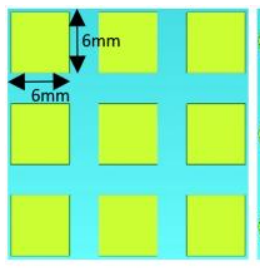

(a)

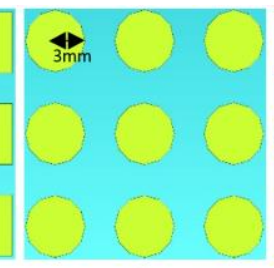

(b)

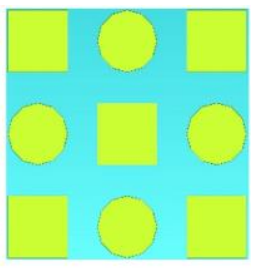

(c)
Fig. 3. The configuration of (a) Design B, (b) Design C and (c) Design D.

Filter circuit is also designed in Advanced Design System (ADS). The purpose of the filter circuit designed is used as circuit modelling to determine the components inductor (L) and capacitor (C) and their values. The Sparameters results of the filter circuit designed is optimized and matched with the S-parameters results that is provided by each design.

\section{Result}

The result of S-parameters (S11 and S21) is simulated for UWB frequency range from $2 \mathrm{GHz}-11 \mathrm{GHz}$. The lower frequency range is simulated from $2 \mathrm{GHz}-6 \mathrm{GHz}$ while higher frequency range is from $6 \mathrm{GHz}-11 \mathrm{GHz}$. For significant changes of $\mathrm{S} 11$ and $\mathrm{S} 21$ results, $2 \mathrm{GHz}-5 \mathrm{GHz}$ and $7 \mathrm{GHz}-11 \mathrm{GHz}$ are presented for lower and higher frequency range respectively.

Copper waveguide (Design A) performs as high pass filter at the frequency larger than cut off frequency. At the frequency that is larger than cut off frequency, the waveguide performs as pass band with $\mathrm{S} 21$ of $0 \mathrm{~dB}$ and very low S11 of mostly $-100 \mathrm{~dB}$. The cut off frequency for Design A occurs at $2.76 \mathrm{GHz}$. The filter circuit is designed to demonstrate the behaviour of waveguide in UWB frequency range in Figure 5. High pass filter by using $\mathrm{L}=475.4 \mathrm{pH}$ is performed at the lower frequency range. Low resistance only is used to show the transmission through waveguide at the higher frequency range with high S21 and low S11. This shows that transmission through copper waveguide can be operated with negligible loss at the frequency larger than the cut off frequency. 


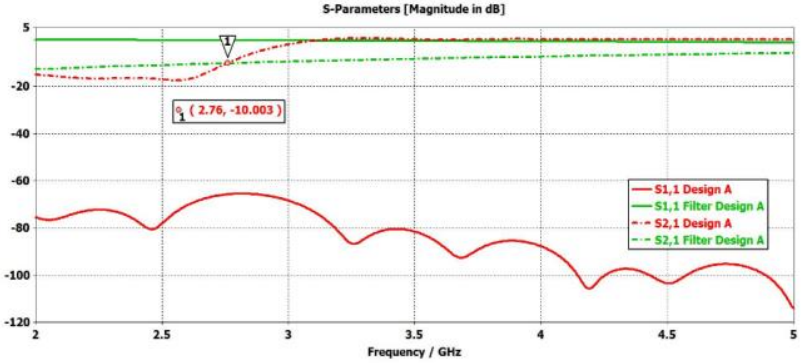

(a)

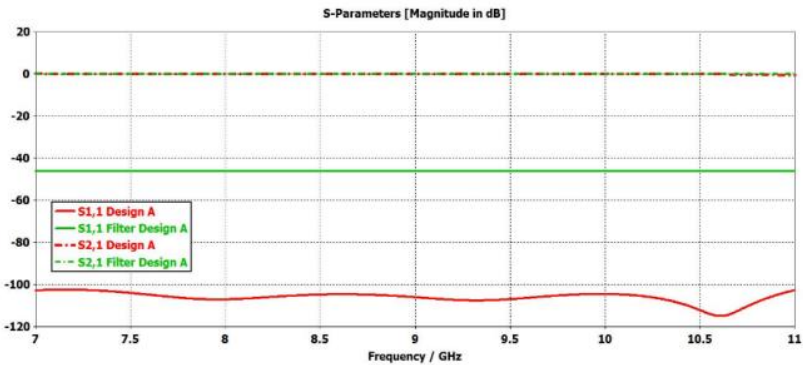

(b)

Fig. 4. The S-parameters result of copper waveguide (Design A) at (a) lower frequency range and (b) higher frequency range.

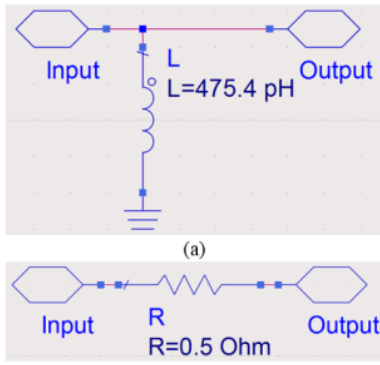

(b)

Fig. 5. The filter circuit of Design A at (a) lower frequency range and (b) higher frequency range.

Figure 6 shows the values of S11 is decreasing while S21 is increasing along the frequency for each design. Compare to Design A, the waveguide with square, circle and mixed square and circle DWS (Design B, Design C and Design D) also perform as high pass filter. They can operate at the frequency around $3 \mathrm{GHz}$ with low $\mathrm{S} 11$ and high S21. The operate frequency for all the DWS designs are near to cut off frequency of Design A. Design B starts to operate at the $2.81 \mathrm{GHz}$ which is the nearest to the cut off frequency. Design $\mathrm{C}$ starts at farthest frequency at $2.95 \mathrm{GHz}$. Meanwhile, hybrid design of Design $\mathrm{D}$ operates at the middle frequency between Design $\mathrm{B}$ and Design $\mathrm{C}$ at $2.87 \mathrm{GHz}$. It performs half of the characteristics from both Design B and Design C. All Design B, C and D also shows the lowest S21 and highest $\mathrm{S} 21$ at $2 \mathrm{GHz}$ and $5 \mathrm{GHz}$ respectively.

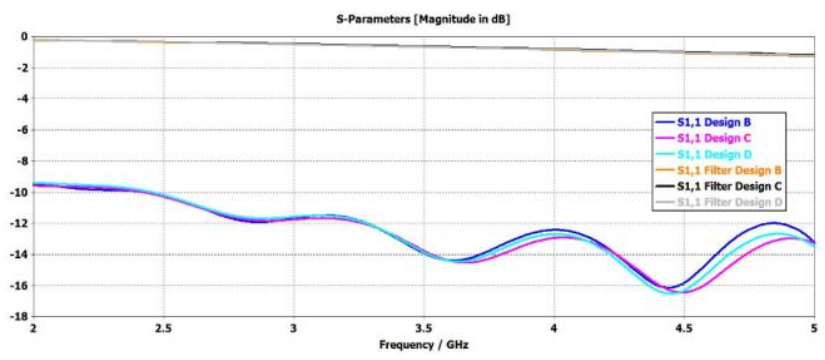

(a)

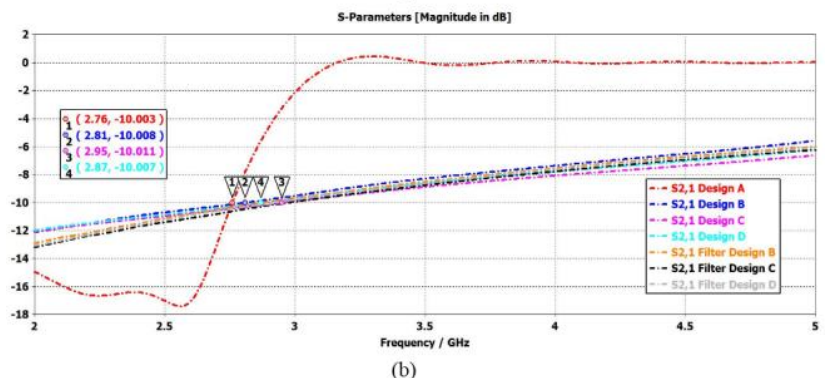

Fig. 6. The results of (a) S11 and (b) S21 at lower frequency range.

The high pass filter is presented by using the $\mathrm{L}$ components for Design B, Design C and Design D as well. As all designs show almost similar results for the S11 and S21, the filter circuits are designed to have slightly change in the value of $\mathrm{L}$ components. It is noticed that the higher the operate frequency, the smaller the value of the $\mathrm{L}$ component. Design $\mathrm{C}$ operates at the highest frequency at $2.95 \mathrm{GHz}$ with the smallest value of L components used, $\mathrm{L}=446 \mathrm{pH}$.

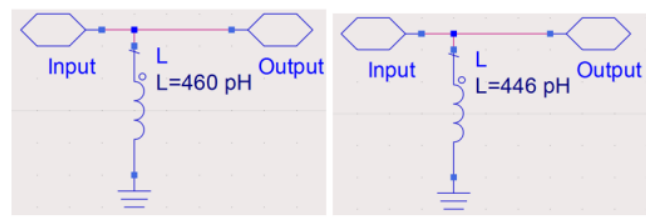

(a) (b)

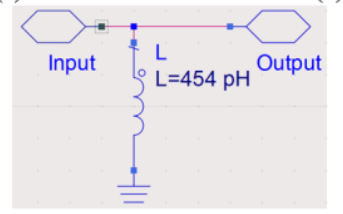

Fig. 7. The filter circuit of (a) Design B, (b) Design C and (c) Design D.

Design A still operates at higher frequency from $7 \mathrm{GHz}-$ $11 \mathrm{GHz}$ with high S21 in Figure 4 . However, all the DWS designs shows stop band performance at higher frequency. High S11 and low S21 are showed at higher frequency for each DWS design. Design B has lowest S21 of $-34.64 \mathrm{~dB}$ occurs at $9.94 \mathrm{GHz}$. Design $\mathrm{C}$ achieves lowest $\mathrm{S} 21$ of $-23.87 \mathrm{~dB}$ at higher frequency of $10.45 \mathrm{GHz}$. The hybrid Design D has lowest S21 of $26.76 \mathrm{~dB}$ at highest frequency of $10.6 \mathrm{GHz}$. All the DWS designs have highest S21 at lower frequency from $7 \mathrm{GHz}-7.14 \mathrm{GHz}$. The highest $\mathrm{S} 21$ is showed by Design C with $-4.4 \mathrm{~dB}$ at $7.14 \mathrm{GHz}$. 


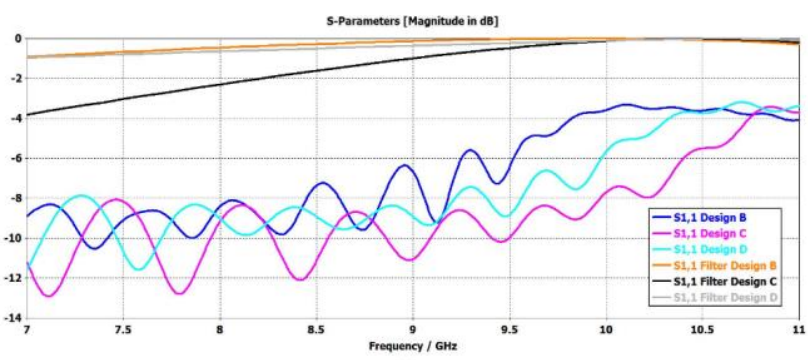

(a)

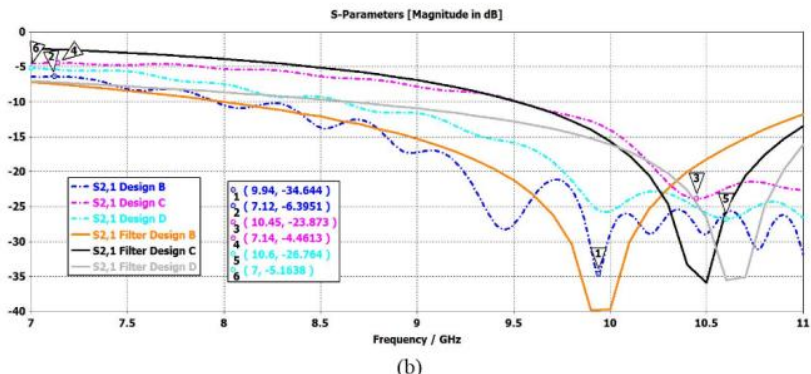

Fig. 8. The results of (a) S11 and (b) S21 at higher frequency range.

The filter circuit of DWS designs for the higher frequency range consists of one $\mathrm{C}$ and LC series tank which are connected in parallel form. The $\mathrm{C}$ contributes to stop frequency of each design which presents more than $-10 \mathrm{~dB}$ for S21 while the LC series tank shows the lowest S21. The LC series tank of Design B has $\mathrm{L}=$ $410 \mathrm{pH}$ and $\mathrm{C}=624 \mathrm{fF}$ with $\mathrm{C}=628 \mathrm{fF}$. Design $\mathrm{C}$ has the smallest $\mathrm{C}=210 \mathrm{fF}$ and $\mathrm{LC}$ series tank with $\mathrm{L}=752 \mathrm{pH}$ and $\mathrm{C}=308 \mathrm{fF}$. Largest $\mathrm{C}=1.25 \mathrm{pF}$ and $\mathrm{LC}$ series tank with $\mathrm{L}=685 \mathrm{pH}$ and $\mathrm{C}=326 \mathrm{fF}$ are used for Design D.

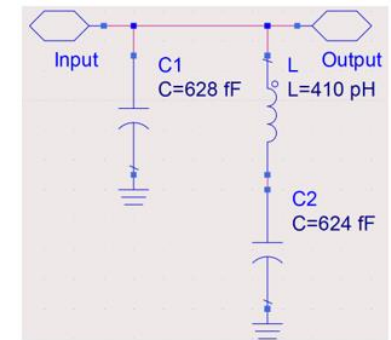

(a)

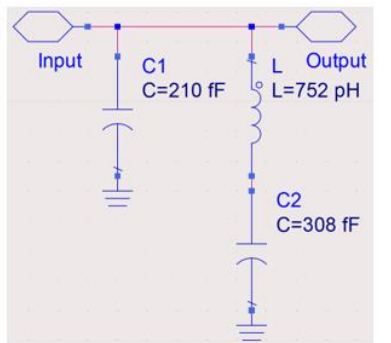

(b)

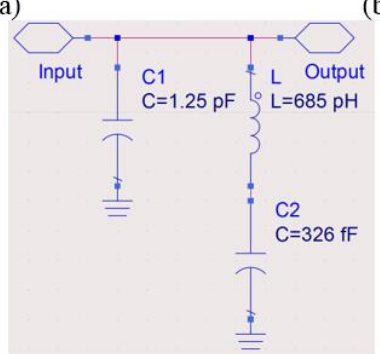

(c)

Fig. 9. The filter circuit of (a) Design B, (b) Design C and (c) Design D.

All the DWS designs operate at middle of UWB frequency range. Design $\mathrm{B}$ shows the narrowest bandwidth for the pass band performance. It achieves bandwidth of $5.19 \mathrm{GHz}$ from $2.81 \mathrm{GHz}-8 \mathrm{GHz}$. Design C performs as band pass filter in the widest bandwidth of $6.55 \mathrm{GHz}$ from $2.95 \mathrm{GHz}-9.5 \mathrm{GHz}$. It also shows the highest S21 of $-4.46 \mathrm{~dB}$ at $7.14 \mathrm{GHz}$. The hybrid Design
D combines both the characteristics from both Design B and Design C. At higher frequency, it shows moderate performance between both designs obviously. It achieves $\mathrm{S} 21$ of $-10 \mathrm{~dB} \mathrm{~S} 21$ at $8.6 \mathrm{GHz}$ in between $8 \mathrm{GHz}$ and $9.5 \mathrm{GHz}$ for Design $\mathrm{B}$ and Design $\mathrm{C}$ respectively. The bandwidth of Design D is improved from $5.19 \mathrm{GHz}$ to $5.73 \mathrm{GHz}$ compares to Design B. The lowest S21 of Design D occurs at highest frequency of $10.6 \mathrm{GHz}$ with $26.76 \mathrm{~dB}$.

\section{Conclusion}

The Defected Waveguide Structure (DWS) with basic structures of square and circle is presented. This proposed waveguide is designed to works as UWB application. Copper waveguide can operate at the frequency larger than cut off frequency and works as high pass filter. Square DWS design presents narrowest bandwidth of $5.19 \mathrm{GHz}$ for pass band performance. Circle DWS design performs as band pass filter in widest bandwidth of $6.55 \mathrm{GHz}$ from $2.95 \mathrm{GHz}-9.5 \mathrm{GHz}$. Hybrid design by mixing both square and circle DWS design improves in bandwidth and achieves bandwidth of $5.73 \mathrm{GHz}$ compares to square DWS design. The monopole antenna will be designed to locate inside the waveguide with DWS in future.

\section{References}

1. Y. D. Wu, G. H. Li, Y. Wei and M. Tong, Progress In Electromagnetics Research Letters, 60, 81-88, (2016)

2. K. Uyama, S. Nishimura, H. Deguchi and M. Tsuji, International Conference on Electromagnetics in Advanced Applications (ICEAA), 728-731, (2016)

3. T. Rowe, P. Forbes, J. H. Booske and N. Behdad, IEEE Transactions on Plasma Science, 45, 654-664, (2017)

4. M. A. Samad and A. K. Hamid, International Conference on Electronic Devices, Systems and Applications (ICEDSA), 1-4, (2016)

5. J. Hummelt, Xueying Lu, Haoran Xu, M. Shapiro and R. Temkin, IEEE International Vacuum Electronics Conference (IVEC), 1-3, (2016)

6. B. Byrne, N. Raveu, N. Capet, G. Le Fur and L. Duchesne, IEEE International Symposium on Antennas and Propagation (APSURSI), 1091-1092, (2016)

7. A. Kandwal, IEEE 5th Asia-Pacific Conference on Antennas and Propagation (APCAP), 277-278, (2016)

8. G. S. Kunturkar and P. L. Zade, International Conference on Communications and Signal Processing (ICCSP), 0281-0285, (2015)

9. S. Gite and D. Niture, International Conference on Information Processing (ICIP), 198-200, (2015)

10. J. Vijayakrishnan and R. P. Dwivedi, ARPN Journal of Engineering and Applied Sciences, 10, (2015) 